\title{
Trypanocidal drug utilization practices in tsetse sup- pression and non-suppression areas of South Omo Zone, Southwestern Ethiopia
}

\author{
Tegegn Tesfaye ${ }^{1 *}$, Tekle Olbamo ${ }^{2}$, Hagos Ashenafi ${ }^{3}$ \\ ${ }^{1}$ Jinka Agricultural Research Center, SNNPR, Jinka, Ethiopia, P.O. Box 96 \\ 2 Jinka University, Department of Animal Science, Jinka, Ethiopia \\ ${ }^{3}$ Addis Ababa University, College of Veterinary Medicine and Agriculture, Bishoftu, Ethiopia \\ * Corresponding author, e-mail: tegetes21@gmail.com
}

\begin{abstract}
Trypanosomosis control in Ethiopia is largely rely on use of available trypanocidal drugs although there are other options such as vector control and use of trypanotolerant hosts. A cross-sectional survey aimed at assessing the knowledge, attitude and practices of trypanocidal drug utilization and constraints of trypanosome infection conducted in tsetse suppression and non-suppression areas of South Omo Zone, Ethiopia. The questionnaire based survey was conducted from November 2018 to May 2019. Descriptive statistics was used to summarize the field data obtained from 184 cattle owners. Sixty (60) of the cattle owners were from suppression area and 124 from tsetse non-suppression area. Accordingly, draft oxen and milking cows respectively from tsetse suppression and non-suppression areas were classes of animals which were given priority in trypanocidal drug treatment. About $79.03 \%$ and $81.7 \%$ of cattle owners respectively from tsetse suppression and non-suppression areas witnessed that they treat their sick animals by themselves; indicating that veterinarians and other animal health experts have very little role in medication of sick animals. Diminazine aceturate (DA) was the main trypanocidal drug preferred by cattle owners in tsetse suppression area while both DA and Isometamidium chloride (ISM) were used in non-suppression areas. About $83.1 \%$ of the respondents from tsetse suppression areas and $86.7 \%$ from non-suppression area reported treatment failures following the use of trypanocidal drugs. Moreover, about $79.61 \%$ and $86.53 \%$ of respondents respectively from tsetse suppression and non-suppression areas observed that drugs obtained from private drug stores were less effective compared to drugs obtained from governmental veterinary clinics. Furthermore, the respondents disclosed that DA was the most
\end{abstract}


horrible trypanocidal drug in showing treatment failures despite high preference by cattle owners. It was also noted that treatment frequency was higher in tsetse suppression areas than non-suppression areas regardless of vector suppression campaign. In conclusion, higher dependency of cattle owners on trypanocidal drugs, limited trypanocidal drug availability in the veterinary pharmaceutical market, frequent trypanocidal drug usage and injection by unskilled herdsmen and owners report on trypanocidal drug treatment failures may point out the issue of trypanocidal drug resistance in the area. Therefore, awareness creation to livestock owners on the effect of misuse of trypanocidal drugs and safe trypanocidal drug usage policy should be put into effect to uphold the effectiveness of currently available trypanocidal drugs.

Keywords: Trypanosomosis; Trypanocidal Drugs; Tsetse suppression; South Omo Zone; Ethiopia

\section{Introduction}

Trypanosomosis is a complex debilitating and often fatal disease, caused by species of unicellular parasite (trypanosome), which is found in the blood and tissues of vertebrate including livestock, wild life and people (Claes et al., 2005). Absence of effective vaccine against trypanosome and absence of coherent environmentally friendly and sustainable vector control strategies makes the disease very complex (Claes et al., 2005; Chitanga et al., 2011; Assefa and Shibeshi, 2018). This disease is controlled by using trypanotolerant host, by controlling of the vector and parasite by using different approaches or a combination of three. However, in poor rural communities, which are mostly affected by the disease, control is mainly relying on the use of trypanocidal drugs. The main drugs used by livestock keepers are Isometamidium chloride (ISM), which has both curative and prophylactic effects, Diminazine Aceturate (DA), which has only curative properties, and homidium salts (chloride and bromide) which has curative and limited prophylactic effect (Van den Bossche, 2000; Giordani et al., 2016).

About 35 million doses of drugs are used in Sub- Saharan Africa (SSA) each year, with ISM, homidium/ethidium bromide and DA representing 40\%, 26\% and $33 \%$ respectively and with about 50-70 million animals at risk from trypanosomosis. All effective trypanocidal drugs developed between 1940 and 1960 have been extensively used for more than half a century (Chitanga et al., 
2011). Due to this extensive use, they can cause the appearance of the drug resistant strains of trypanosomes and it is of utmost importance that measures are taken to avoid or delay the development of resistance and to maintain the efficacy of the currently available drugs (Claes et al., 2005; Chitanga et al., 2011).

Despite the high usage of these veterinary trypanocides and increasing drug resistance problems, the interest of pharmaceutical industries to invest in research for developing new products remains low, leaving farmers to rely on the existing drugs (Cross, 2001; Cossic et al., 2017). Due to the privatization of veterinary services in most parts of Africa, farmers have easy access to trypanocides and this has resulted in rampant misuse and under-dosage of the medications, actions that have been blamed for the emergence of trypanocidal drug resistance. Currently, trypanocidal drug resistance has been reported in 18 Sub-Saharan African countries. However, most of these reports seem to be confined to areas where the disease is endemic (Delespaux et al., 2008).

In Ethiopia, bovine trypanosomosis and its cyclical vectors were widely distributed in Western and Southwestern part of the country with annual estimated losses of $\$ 200$ million, in terms of mortality and morbidity losses in livestock and the costs of controlling the disease (IAEA, 1996). Similar to other SSA countries, trypanocidal drug resistance is reported from different parts of Ethiopia by using either a mice experiment model or block treatment methods in field conditions. Accordingly, multiple drug resistant T. congolense populations (resistant to DA and ISM) in naturally infected cattle of Metekel district (Afewerk et al., 2000) and T. congolense populations resistant to DA, ISM and homidium chloride were reported in cattle from Ghibe (Mulugeta et al., 1997). Moreover, T. congolense isolates resistant to DA and ISM were found in Ghibe valley Moti et al. (2012) and Bedelle and Sodo (Chaka and Abebe, 2003). Similarly, Tewelde et al. (2004) reported ISM resistant T. congolense, T. vivax and T. brucie in cattle from upper Didessa valley of Western Ethiopia. Additionally, ISM and homidium resistant T. evansi was reported from Tigray and Afar regions (Mekonnen et al., 2018). Despite of these numerous researches on trypanocidal drug resistance, some parts of the country, which are endemic to trypanosomosis and its vectors, are devoid of information about trypanocidal drug resistance and drug utilization practice. 
South Omo zone is one of pastoral areas in Ethiopia, which owns huge livestock resources. Although there is scarce data on trypanosomosis, trypanocidal drug resistance and its utilization practice among livestock owners, it is suspected that South Omo zone is one of endemic area, which shares favorable conditions for the occurrence of bovine trypanosome infection, and its control depends mainly on use of available trypanocidal drugs. Furthermore, demand and supply of trypanocidal drugs was unbalanced due to huge cattle population and limited veterinary pharmaceuticals in the area. This in turn exposes the herdsmen to purchase poor quality trypanocides from unauthorized routes (personal communication). Moreover, extensive treatment of sick animals by untrained livestock owners and use of poor quality trypanocides might aggravate the extent of trypanocidal drug resistance and its associated problems. Therefore, the objective of this survey was to assess the knowledge, attitudes and trypanocidal drug utilization practices of livestock owners in South Omo Zone, as initial step for further study of trypanocidal drug resistance.

\section{Materials and methods}

\section{Description of study area}

South Omo zone is situated in the Southern Nations, Nationalities and Peoples Region (SNNPR) of Ethiopia. The zone is bordered on the South by Kenya, on the Southwest by the Ilemi Triangle, on the West by Bench Maji, on the Northwest by Keffa, on the North by Konta, Gofa and Basketo on the Northeast by the Dirashe and Konso Special Districts, and on the East by the Oromia Region. The administrative center of South Omo zone (Jinka city) is located at $750 \mathrm{Km}$ and $525 \mathrm{Km}$ from South of Addis Ababa and Hawassa respectively (SOZLFD, 2018). 


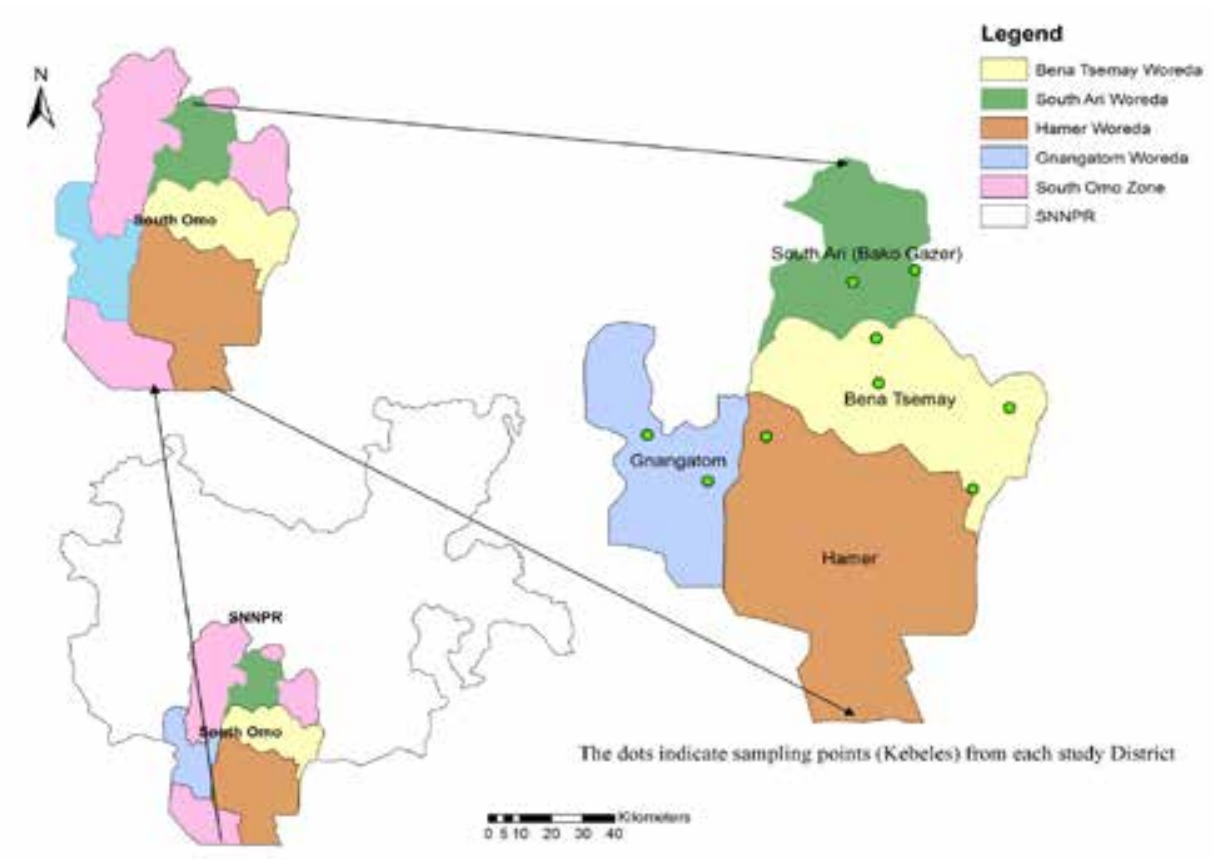

Figure 1. Map showing study zone on regional map (left bottom) and four study districts (right) (Designed by using ArcGIS Version 10.2.2 by taking GPS points of each study sites).

According to population projections of Central Statistical Agency of Ethiopia (CSA, 2013), more than 700,000 people were projected to be living in the South Omo zone which has an area coverage of $24,249 \mathrm{Km} 2$. Similarly, agricultural sample survey indicated the total cattle, sheep and goat population of South Omo zone (in million) as $1.75,1.55$ and 2.88 respectively (CSA 2017). There are eight (8) districts representing South Omo zone, which have diverse ethnic groups. Out of 56 ethnic groups found in the SNNPR, 16 ethnic groups were from South Omo zone.

The zone is located between $4^{0} 43^{\prime}$ North to $6^{0} 46^{\prime}$ North latitude \& $35^{\circ} 79^{\prime}$ East to $36^{\circ} 06^{\prime}$ East longitude, and found between $376 \mathrm{~m}$ and 3,500 m. a. s. 1 . with mean annual rainfall ranging from $400 \mathrm{~mm}$ to $1,600 \mathrm{~mm}$. It has a diverse agro-ecological zone ranging from hot arid to the tropical humid with average temperature ranging from minimum of $10.1^{\circ} \mathrm{C}$ to maximum $27.5^{\circ} \mathrm{C}$ (SOFED, 2012). In the study area, rain is erratic and usually bimodal occurring from 
September to December and from March to May (NMSA, 2005; FEWSNET, 2012).

Mixed crop-livestock farming is the main source of livelihoods in agro-pastoral districts of the zone (Debub Ari, Semen Ari, Male and few areas of Benatsemay district) where maize, sorghum and legumes are the major subsistence crops, and onion, cabbage and cardamom are the cash crops. Other crops include root crops (yams, sweet and Irish potatoes, cassava, enset, "godere"); fruit trees and small-scale horticulture (vegetables) are also available in these agro-pastoral districts. Out of eight districts in the zone, four districts namely Hammer, Dasenech, Gnangatom and Selamago are occupied largely by pastoralists even though there are few pastoralists practicing crop cultivation near Omo River after the river get out from the farming land following heavy rain which is locally known as 'Omo shish'. The livelihood of these pastoral districts depends on livestock rearing which are mainly local breeds of both large and small ruminants.

Regarding livestock health infrastructures, the zone has seven (7) veterinary clinics, six of which are found in six different districts under the zone and one in the zonal center (Jinka). The zone also has 86 animal health posts, 9 veterinarians, 301 animal health experts and 364 community animal health workers (CAHWs). According to SOZLFD (2018), there are fifteen (15) veterinary drug shops situated in different districts of the zone.

Glossina vector (tsetse fly) suppression activities in South Omo zone was started in 2013 by Southern Tsetse Eradication Program (STEP) based on initial entomological survey conducted on 2012 by the program office. According to the initial survey, the vector density of South Omo zone was found to be 51.5 F/T/D; dominantly of G. pallidipes and few undefined species (STEP, 2012). After this initial survey, four districts namely Debub Ari, Benatsemay, Male and Selamago, which were suspected to be highly infested by the Glossina vector were selected and vector suppression activity was initiated by using deltamethrin (1\%) pour-on technique with regular vector survey between each suppression campaign. For the sake of this study, the above mentioned four districts were taken as tsetse suppression areas. Whereas, the remaining districts (Hamer, 
Dasenech, Semen Ari and Gnangatom), which were not included in vector suppression campaign of STEP were classified as tsetse non-suppression areas.

\section{Study design and methods of sampling}

Cross-sectional questionnaire survey was used to undertaken this study. Representative study districts and Kebeles were purposively selected based on ease of access and sake of convenience. From selected Kebeles, representative respondents (livestock owners) were selected by simple random method by using their lists from Kebeles administration.

\section{Sample size determination}

The sample size for trypanocidal drug utilization practice survey was calculated by the formula given below to calculate survey sample size in social research according to Taherdoost (2017).

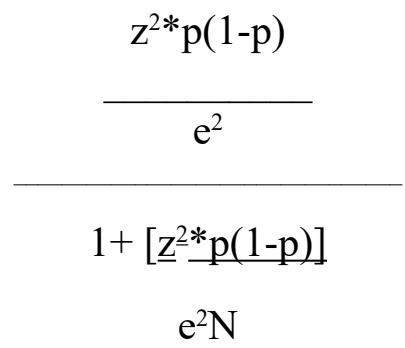

Where:

$\mathrm{N}=$ total population size of study districts which was obtained from (CSA, 2007)

$\mathrm{E}=$ margin of error (equal to 0.05 or $1 / 20$ )

$\mathrm{z}=\mathrm{z}$-score indicating the number of standard deviations a given proportion is away from the mean whose value is equal to 1.96 for $95 \%$ confidence level

$\mathrm{p}=$ percentage of my sample that picks a particular answer. Accordingly, 184 agro-pastoralists/pastoralists, 124 and 60 respectively from tsetse suppressing and non-suppressing districts were participated in questionnaire survey. 


\section{Data collection}

A structured questionnaire was administered to agro-pastoralists/pastoralists to collect data on problems of trypanosomosis and trypanocidal drug utilization. The questionnaire comprised of respondent's background, knowledge about trypanosomosis, information about trypanocidal drugs (source, drug preference, frequency of treatment, treatment failure, and cost/year) and any death occurrence due to trypanosomosis. Prior to dissemination of questionnaire to respective participants, the questionnaire was translated in to Amharic version for easy translation to local languages and then to the three major local languages (Ari, Bena and Hammer). Moreover, for compliance of ethical standard, participants were briefed about the objectives of the survey and confidentiality of information they provide and all participants gave their oral informed consent before the interview. In addition to primary data sources, secondary information from recorded data at study zonal, district and Kebele level were also used.

\section{Data analysis}

Data recorded during questionnaire survey was coded and entered into Microsoft Excel Spread Sheet to create a database and were imported to SPSS version 20 for descriptive analysis. Descriptive statistics like means, frequencies and percentages were calculated for different parameters.

\section{Results}

The findings of questionnaire survey declared that majority of the respondents were male and illiterate. Accordingly, $84.67 \%$ and $74.19 \%$ of the respondents in tsetse suppression area were male and illiterate respectively. Likewise, $86.7 \%$ and $88.3 \%$ of respondents from tsetse non-suppression areas were male and illiterate respectively.

About $63.7 \%$ of the respondents from tsetse-suppression area gave priority to draft oxen in trypanosomosis treatment. However, $58.3 \%$ of interviewee from non-tsetse suppression areas mentioned that they give priority to milking cow in trypanosomosis treatment. Moreover, about $63.70 \%$ and $81.7 \%$ of respondents respectively from tsetse suppression area and non-suppression areas obtain trypanocidal drugs from private veterinary drug shops. Veterinarians and 
other animal health experts have very little role in treatment of animals with trypanocidal drugs and other medications in the study area as $79.03 \%$ and $81.7 \%$ of respondents respectively from tsetse suppression area and non-suppression areas witnessed that treatment was given by themselves (Figure 2).

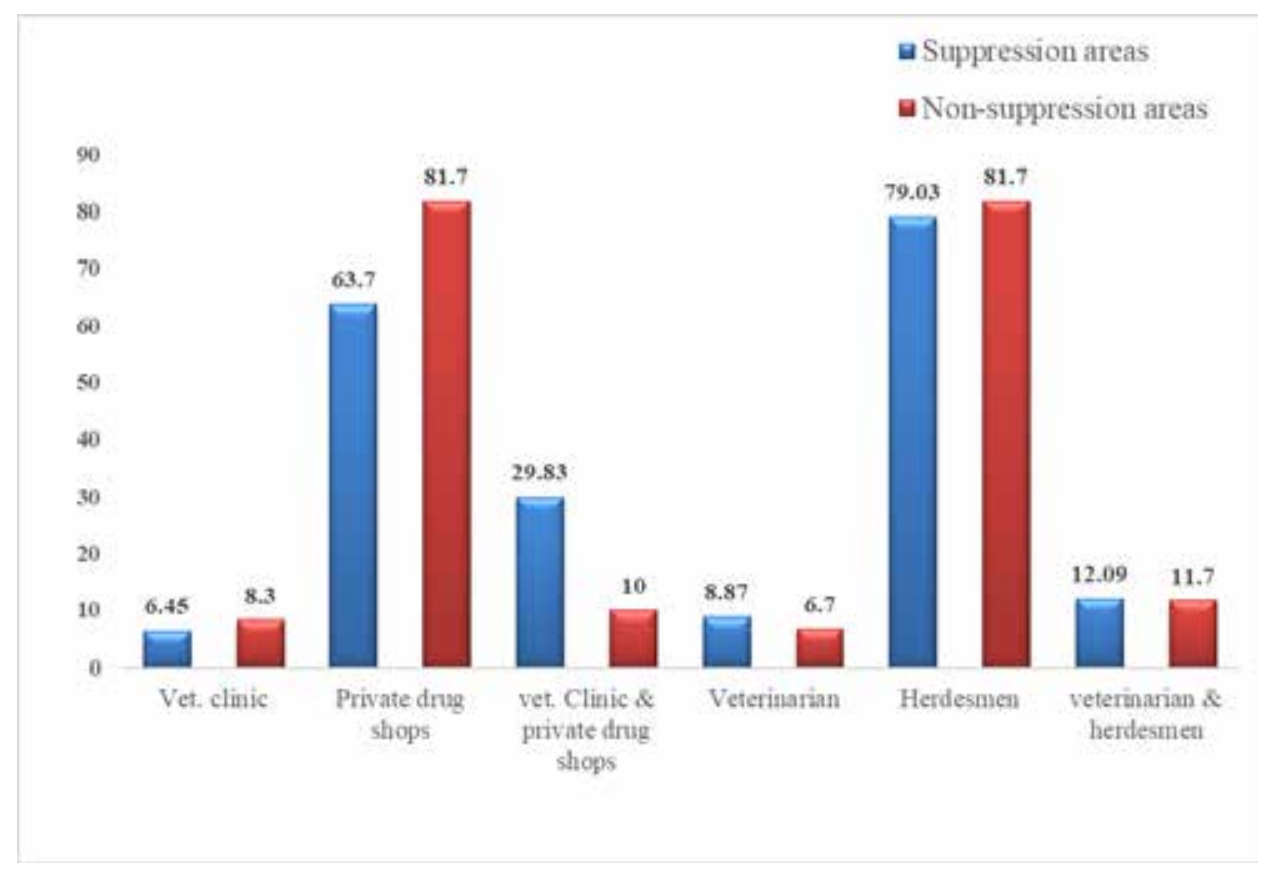

Figure 2. Source of trypanocidal drugs and respondent's access to veterinary service in tsetse suppression and non-suppression areas of South Omo Zone

Diminazine aceturate (DA) is the most preferred drug by herd owners of tsetse non-suppression areas as affirmed by $70 \%$ of respondents which is followed by both DA and ISM (16.7\%) (Figure 3 B). However, in tsetse suppression area both DA and ISM (62.1\%) occupy the first place in their preference followed by DA (18.7\%) and both DA and homidium (5.6\%) (Figure $3 \mathrm{~A}$ ). 

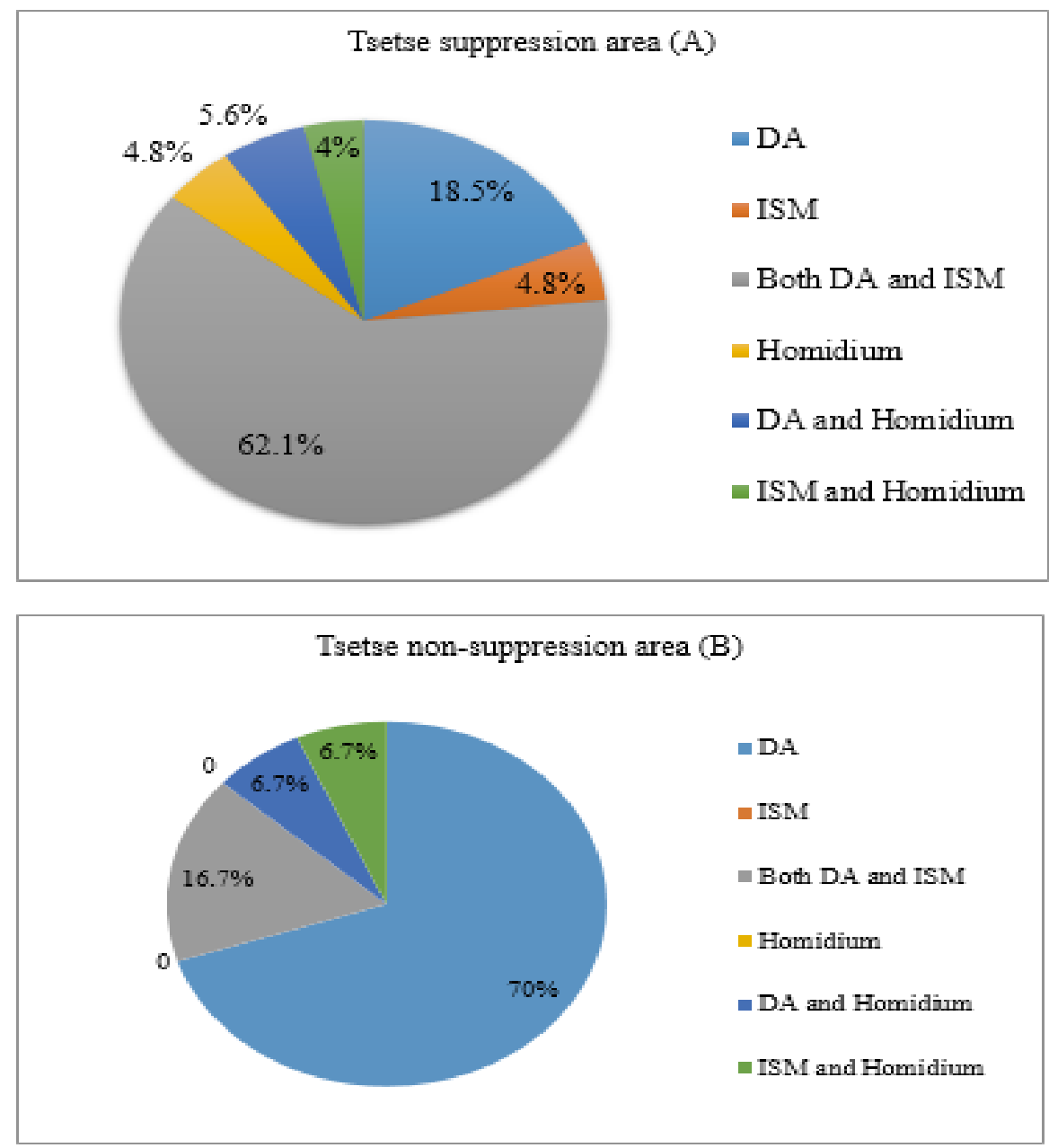

Figure 3. Trypanocidal drug preference by respondents

Respondents from both tsetse suppression area (81.5\%) and non-suppression areas $(73.3 \%)$ replied that their animals show frequent symptom/sign of trypanosome infection such as erection of hair, erection of hair and depression and erection of hair and dried feces (Table 2) during wet season as compared to dry season. With occurrence of disease symptom, the owners treat their animals with their own preferred trypanocidal drugs. However, if the animals continue showing the disease symptoms following treatment, it is perceived as failure 
of the trypanocidal drug to cure the patient. This condition was witnessed by $83.1 \%$ and $86.7 \%$ of the respondents respectively from tsetse suppression and non-suppression areas. These failures of trypanocidals to cure the patient were most common when the origin of the drug is from private drug shops compared to drugs from governmental veterinary clinic as the cattle owners' response indicated (Table 1).

Table 1. Season of trypanosomosis occurrence, occurrence of treatment failure and source of trypanocidals with failure report

\begin{tabular}{llcc}
\hline Description of interview & Response & Response rate (\%) \\
\cline { 3 - 4 } & & TSA & TNSA \\
\hline $\begin{array}{l}\text { Season of frequent } \\
\text { trypanosomosis occurrence }\end{array}$ & Dry & 12.1 & 18.3 \\
& wet & 81.5 & 73.3 \\
Encountering failure of & Yes & 6.5 & 8.3 \\
trypanocidal drug & No & 83.1 & 13.3 \\
Source of failure trypanocidal in both seasons & Gov. veterinary clinic & 16.9 & 9.6 \\
& Private drug stores & 16.5 & 86.5
\end{tabular}

Diminazine aceturate is the most dominant trypanocidal showing failures after treatment which was respectively acknowledged by $54 \%$ and $70 \%$ of respondents from tsetse suppression and non-suppression areas districts followed by both DA and ISM in both areas (Figure 4). The frequency of trypanocidal treatment per year is higher in tsetse suppression area as half of the respondents replied that they treat their animals four times a year followed by three times a year (25.8\%). However, in tsetse non-suppression areas, trypanocidal medication of two times a year $(60 \%)$ is maximal followed by three times a year (16.7\%) as interviewee confirmed (Figure 4). 


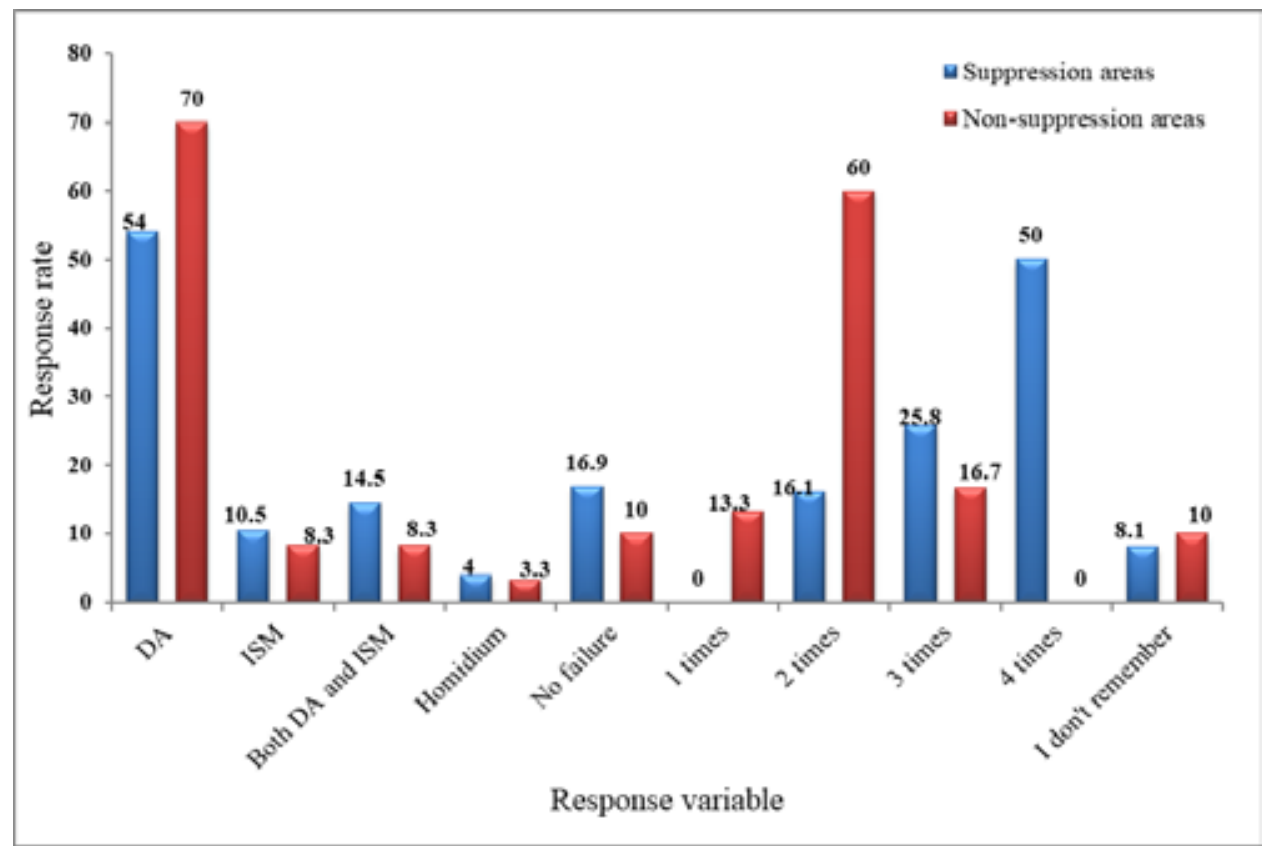

Figure 4. Trypanocidal drug treatment response and frequency of treatment per year

Erection of hair (47.58\% and 65\% respectively in tsetse suppression area and non-suppression areas) was the dominant symptom manifested by cattle owners as indicative of trypanosomosis, which was followed by concurrent occurrence of erection of hair and depression in both study areas. In tsetse suppression area, although the cattle owners invest more than 500 ETB to purchase trypanocidal in a year, about $39.51 \%$ ascertained that they repeatedly encountered death due to the disease in the past five years. The cattle owners response indicated less average cost on trypanocidal purchase in tsetse non-suppression area which ranged between 100-200 ETB per year as compared to $>500$ ETB per year in tsetse suppression area (Table 2). The respondents from tsetse non-suppression area also affirmed that they encountered less death due to trypanosomosis in past five years as witnessed by $73.3 \%$ of the respondents (Table 2). 
Table 2. Interviewee response on drug costs per year, cattle deaths and observed symptoms of trypanosomosis

\begin{tabular}{|c|c|c|c|c|c|}
\hline \multirow{2}{*}{$\begin{array}{l}\text { Description of } \\
\text { interview }\end{array}$} & \multirow[t]{2}{*}{ Categories } & \multicolumn{2}{|c|}{ Frequency } & \multicolumn{2}{|c|}{ Percentage (\%) } \\
\hline & & TSA & TNSA & TSA & TNSA \\
\hline \multirow{7}{*}{$\begin{array}{l}\text { Cost for trypanocidal } \\
\text { per year }\end{array}$} & 50-100 ЕТВ & 21 & 13 & 16.93 & 21.7 \\
\hline & 100-200 ETB & 20 & 20 & 16.12 & 33.3 \\
\hline & 200-500 ETB & 31 & 9 & 25.00 & 15.0 \\
\hline & $>500 \mathrm{ETB}$ & 32 & 9 & 25.80 & 15.0 \\
\hline & I don't know & 20 & 9 & 16.12 & 15.0 \\
\hline & Total & 124 & 60 & 100.0 & 100.0 \\
\hline & Yes & 49 & 16 & 39.51 & 26.7 \\
\hline \multirow{2}{*}{$\begin{array}{l}\text { Death due to } \\
\text { Trypanosomosis in past } \\
5 \text { years }\end{array}$} & No & 75 & 44 & 60.48 & 73.3 \\
\hline & Total & 124 & 60 & 100.0 & 100.0 \\
\hline \multirow{5}{*}{$\begin{array}{l}\text { Indicative signs/ } \\
\text { symptoms of } \\
\text { trypanosomosis }\end{array}$} & $\begin{array}{l}\text { Erection of hair and } \\
\text { diarrhea }\end{array}$ & 12 & 0 & 9.67 & 0.00 \\
\hline & Erection of hair & 59 & 39 & 47.58 & 65.0 \\
\hline & $\begin{array}{l}\text { Erection of hair and } \\
\text { depression }\end{array}$ & 45 & 13 & 36.29 & 21.7 \\
\hline & $\begin{array}{l}\text { Erection of hair and } \\
\text { drying of faces }\end{array}$ & 8 & 8 & 6.45 & 13.3 \\
\hline & Total & 124 & 60 & 100.0 & 100.0 \\
\hline
\end{tabular}

\section{Discussion}

The current study revealed that trypanosomosis (locally known as "Kusupho", meaning the disease caused by flies) is one of the major bottlenecks for livestock production in both tsetse-suppressing and non-suppressing areas of South Omo Zone. All the respondents (100\%) from both study areas witnessed that their animals had encountered the disease for decades. Similar reports about trypanosomosis was revealed from tsetse infested and non-tsetse infested areas of Northwest Ethiopia (Dagnachew et al., 2017), Abbay basin areas of Northwest Ethiopia (Dagnachew, 2004), Tselemti Woreda of Tigray region (W/ yohannes et al., 2010), Western Ethiopia (Tewelde et al., 2004), South Western Ethiopia (Tekle et al., 2018), and Northern Ethiopia (Birhanu et al., 2015). 
This study has also indicated that cattle owners had different approach in giving priority to their animals from treatment point of view. Animal owners from tsetse suppression areas give priority to draft oxen in treatment of trypanosome infection and reasoned that oxen are the most valuable class of animals in agricultural land preparations since they are practicing mixed farming system and the market fetch value of oxen is higher than other class of animals even after long term serving on traction. Previous report of Seyoum et al. (2013) indicated similar condition of bovine trypanosome infection severity and more investment of owners to treat draft oxen than other class of animals in Baro-Akobo and Gojeb river basins in SNNPR, Southwestern Ethiopia. On the contrary, to tsetse suppression areas, respondents from tsetse non-suppression areas of current study gave priority to milking cow in treatment of trypanosomosis and stated that milk is their primary base of livelihood since most of respondents from tsetse non-suppression areas were pastoralists who rear livestock for their livelihood.

Private drug shops were the major suppliers of trypanocidal drugs for the residents of South Omo Zone (for both tsetse suppression and tsetse non-suppression areas) followed by both sources together (government vet clinic and private drug shop) and government veterinary clinics. Due to strict control made on unauthorized drug sellers (personal communication with each study district's livestock and fishery department head), the vet drug from this route is negligible in the study area. Moreover, community awareness creation on disadvantage of unauthorized drug usage and strong participation of authorized drug sellers play key role in minimizing unauthorized veterinary drug sources in the area. Consistent report was declared from tsetse- infested areas of Jabitehenan by Dagnachew et al. ( 2017) where 48\% of his interviewee responded private drug shops as their primary drug route. However, reports disagree with present study was declared from Guraghe zone of SNNPRS and Jimma zone of Oromia region by Tekle et al. (2018) and Chewaka settlement station and Bikiltu Didessa peasant associations of South West Ethiopia by Anberber et al. (2014) which stated that unauthorized route as primary source of trypanocidal drug.

Assessment on person responsible for injection of sick animals with trypanocidal drugs indicated that $79.03 \%$ and $81.7 \%$ of respondent; respectively from tsetse suppression and tsetse non-suppression areas treat their animals when 
sick. Only $8.87 \%$ and $6.7 \%$ of the respondents respectively from tsetse suppression and tsetse non-suppression areas send their sick animals to veterinary clinic or animal health post to be treated with veterinarian or other trained personnel. The cattle owners reasoned out that they were far away from animal health post and veterinary clinics so that their only chance to save sick animal is treating by themselves. According to respondents, one animal health expert or community animal health worker (CAHW) was assigned for clusters of Kebeles (one cluster containing 3-4 Kebeles) (SOZLFD, 2018). Therefore, waiting animal health expert's service is very difficult to save diseased animals. Person responsible for trypanocidal injection in the current study was found in agreement with previous studies of Denu et al. (2012); Hadush et al. (2014); Tsegaye (2014) and Tekle et al. (2018).

Diminazine aceturate (DA), locally known as "Kacho" was the major drug of choice for treatment of animals with trypanosomosis symptom in tsetse nonsuppression areas as DA is cheaper than ISM ("Singula") in the private drug stores. However, it was both DA and ISM in tsetse suppression areas according to current survey report. DA preference by cattle owners of tsetse non-suppression areas agree with reports of Van den Bossche et al. (2000) and Tewelde et al., (2004) who stated that most farmers prefer to use DA to ISM. Similarly, DA was the drug of choice for non-tsetse infested area residents of North West Ethiopia (Tsegaye 2014). Tsetse suppression areas drug preference of the present study was similar to Tsegaye (2014) report from tsetse-infested areas of North West Ethiopia who reported that majority (68\%) of the respondents prefer both ISMM and DA. Both DA and ISM preference in tsetse suppression area of South Omo zone might be associated with the cattle owners' belief in which they perceive treating the two drugs interchangeably brings better achievement in the control of trypanosomosis. Moreover, easy availability of both drugs in all available sources of veterinary pharmaceuticals of tsetse suppression area may increase their preference by cattle owners.

Trypanocidal treatment frequency of 4 times per year (50\%) and two times per year $(60 \%)$ was reported respectively from tsetse suppression areas and tsetse non-suppression areas of current study area. Comparable treatment frequencies were reported from tsetse free areas of North West Ethiopia (1-3 times per year) by Tsegaye (2014) and Metekel district of Benshangul Gumuz region (three times per year) by Afewerk and collegues (2000). On the contrary, very 
higher treatment frequency reports were disclosed by Dagnachew (2004) in the lowland (3-4 times per month) and midland (1-2 times per month) areas of Abbay basin, Tewelde et al., (2004) in Western Ethiopia (2.5-3.5 times per month), Tsegaye (2014) in tsetse-infested areas of North West Ethiopia (> 10 times per year) and Seyoum et al. (2013) in Baro-Akobo and Gojeb River basins (6 times per year).

Higher treatment frequency in tsetse suppression areas compared to tsetse non-suppression areas in current study might indicated higher challenge of the disease due to non-sustainability and less participation of community on vector suppression activities. Close interaction of wild life conservation areas with tsetse suppression areas may increase the chance of animals to be infected since wild animals in conserved areas may act as source of infection. This in turn increases the frequency of treatment in the area as compared to tsetse non-suppression areas. Moreover, easy access to trypanocidal drug sources may also play great role in increased frequency of treatment since most of the owners in tsetse suppression areas were close to zonal and district cities where all sources (veterinary clinic and private drug vendor shops) of trypanocidal drugs were located.

High trypanosomosis occurrence during wet season according to respondents of current study was similar with the report of Abebe, (2018). The respondents of this study associated with high wet season occurrence of the disease with increased fly number in the area following rain since they associate the disease with fly population ("Kusupho" in local language meaning disease caused by flies). They also explained that there was a tree called "Gadaq" in local language whose flower can highly attract the flies (including tsetse) during wet season so that their animals were easily infected by the disease caused by flies ("kusupho"). On the contrary, equal occurrence of trypanosomosis in both dry and wet seasons was reported previously by Tewelde et al., (2004) and Afewerk and collegues (2000). from Ethiopia and Ngare and Mwendia (2000) from Kenya.

Treatment failure was witnessed by $83.1 \%$ and $86.7 \%$ of the interviewee from tsetse suppression areas and tsetse non-suppression areas respectively. Higher treatment failure of present study area might be hugely associated with injection of trypanocidal drugs by unskilled herdsmen and erroneous dilution 
of trypanocidals. Additionally, it also might be associated with under dosage and use of poor quality of trypanocidals to treat the animals. Similarly, Tekle et al. (2018) survey report indicated that all of his respondents perceived the occurrence of treatment failure after medication. The current survey indicated that drugs from authorized private drug stores show more failure than those drugs from government veterinary clinics. However, reports of Tekle et al. (2018) pointed that trypanosomosis treatments were more likely to be successful when the drugs are sourced from both government veterinary clinics and authorized private sources, although he and his co-workers found $27.3 \% \mathrm{DA}$ and $29.4 \%$ ISM sampled from both authorized and unauthorized drug sources were non-compliant due to insufficient active ingredients.

DA is the most horrible trypanocidal drug that exhibit treatment failure in current study areas of South Omo Zone as approved by $54 \%$ and $70 \%$ participant respondents, respectively from tsetse suppression areas and tsetse nonsuppression areas. Different reports from various angles of Ethiopia as well as other Sub-Saharan African countries revealed this situation through assessment as well as via experimental studies by using laboratory animals. Experimentally Moti et al. (2012) in Gibe valley, Chaka and Abebe (2003) in Gibe valley, Bedelle and Sodo, Mekonnen et al. (2018) in Tigray and Afar and Afewerk et al. (2000) in Metekel reported single as well as multiple trypanocidal drug resistant occurrence. Low market price of DA when compared with ISM, its high preference by cattle owners of the study area (especially of tsetse nonsuppression areas) and lack of dosage knowledge as well as administration by unskilled personnel may predispose this trypanocide for treatment failure. Despite of numerous reports on resistant development against DA by trypanosome species, Mekonnen and colleagues reported comparative advantage of DA over ISM by completely curing mice infected with T. evansi isolated from dromedary camel in Tigray and Afar, Northern Ethiopia which makes DA as drug of choice for treatment of Surra (Mekonnen et al., 2018).

Higher treatment cost in tsetse suppression areas as compared to tsetse nonsuppression areas in this study may indicate high challenge of the disease to the residents of tsetse suppression area although there were vector control activities and it shows more reliance of herdsmen on trypanocidal drug. Moreover, it may indicate better awareness of cattle owners in prophylactic treatment of non-sick animals in tsetse suppression areas, which may increase annual cost for trypanocidal. Furthermore, increased access of veterinary health 
provision centers such as veterinary clinic, animal health post and veterinary drug shops in tsetse suppression areas may increase the frequency of trypanocidal drug purchase per year. Similar assumption was reported by Uilenberg and Boyt (1998) who said that the number of treatments over a year reflects the magnitude of trypanosomosis challenge in an area. Mean annual treatment cost report for trypanosomosis from Gimbo and Guraferda of Baro-Akobo and Gojeb river basins in SNNPRS by Seyoum et al. (2013) was almost similar with the current treatment cost report from tsetse non-suppression areas but it was lower than annual treatment cost of respondents from tsetse suppression areas.

\section{Conclusion}

This study result leads to the conclusion of higher dependency of cattle owners on trypanocidal drugs and frequent trypanocidal drug usage and injection by unskilled herdsmen was common in South Omo Zone. Furthermore, limited trypanocidal drug availability in the market in conjunction with owners report on trypanocidal drug treatment failures may point out the issue of trypanocidal drug resistance in the area. Therefore, awareness creation to livestock owners on the effect of misuse of trypanocidal drugs and safe trypanocidal drug usage policy should be engaged to uphold the effectiveness of currently available trypanocidal drugs. Moreover, participatory vector control activities and further trypanocidal drug resistance and efficacy investigation should be conducted in the area to discern the status of available trypanocidal drugs.

\section{Limitations of the study}

Further information might be generated especially from tsetse non-suppression areas if the number of participants (herd owners) in the survey were higher than those used in our study. Additionally, brand identification of circulating trypanocidals in the area, especially trypanocidal drugs that shown treatment failure was not covered by this study due to the interviewee knowledge hindrance to identify each brand through our questionnaire survey, which needs further exploration along with their efficacy study. 


\section{Acknowledgements}

The authors would like to acknowledge Southern Agricultural Research Institute (SARI) for funding this research and Livestock Research Directorate of Jinka Agricultural Research Center (JARC), Jinka University (JKU) and Jinka Veterinary laboratory for further logistic contribution. The contribution by the study participants is highly acknowledged, without their collaborative effect the study would not be possible.

\section{Conflict of interest}

The authors declare that there is no conflict of interest.

\section{References}

Abebe, B.H., 2018. Epidemiology of bovine trypanosomosis in selected districts of Benshanhul Gumuz Region with emphasis on Trypanosoma congelense trypanocidal drug resistance and alternative therapy in mice. MVSc thesis, Addis Ababa University, College of Veterinary Medicne and Agriculture, Bishoftu, Ethiopia.

Afewerk, Y., Clausen, P.H., Abebe, G., Tilahun, G., Mehlitz, D., 2000. Multiple-drug resistant Trypanosoma congolense populations in village cattle of Metekel district, north-west Ethiopia. Acta Trop., 76(3), 231-238.

Anberber, M. Z., Basu, A., Asfaw, Y., 2014. Socioeconomic assessment of a tsetse and trypanosomosis control program in Southwest Ethiopia. J. Adv. Vet. Res., 4(3), $126-134$.

Assefa, S., and Shibeshi, W., 2018. Drug resistance in African animal trypanosomes: A review. Afr. J. Microbiol. Res., 12(7). 380-386.

Birhanu, H., Fikru, R., Said, M., Kidane, W., Gebrehiwot, T., Hagos, A., Alemu, T., Dawit, T., et al. 2015. Epidemiology of Trypanosoma evansi and Trypanosoma vivax in domestic animals from selected districts of Tigray and Afar regions, Northern Ethiopia. Parasite Vectors. 8(2015).

Cattand, P., Desjeux, P., Guzmán, M.G., Jannin, J., Kroeger, A., Medici, A., Musgrove, P., Nathan, M.B., Shaw, A., Schofield, C.J., 1994. Tropical diseases lacking adequate control measures : Dengue, Leishmaniasis , and African trypanosomiasis. In: Jamison et al. (Ed.), Disease Control Priorities in Developing Countries, $2^{\text {nd }}$ edition. New York, pp. 451-466.

Chaka, H. and Abebe, G., 2003. Drug resistant trypanosomes: a threat to cattle production in the southwest of Ethiopia. Rev. Elev. Med. Vet. Pays Trop., 56(1-2), 33-36.

Ethiop. Vet. J., 2020, 24 (2), 90-111 
Claes, F., Büscher, P., Touratier, L., Goddeeris, B.M., 2005. Trypanosoma equiperdum: master of disguise or historical mistake? Trends Parasitol., 21(7), 316-321.

Cossic, B.G.A., Adjahoutonon, B., Gloaguen, P., Dibanganga, G.L., Maganga, G., Leroy, P., Macleod, E.T., Picozzi, K., 2017. Trypanosomiasis challenge estimation using the diminazene aceturate ( Berenil ) index in Zebu in Gabon. Trop. Anim. Hlth. Prod., 49(3), 619-624.

Cross, G.A.M., 2001. African trypanosomes in the 21st century: What is their future in science and in health? International journal for parasitology. 31(5-6), 427-433.

CSA (Central Statistical Authority), 2017. Federal Democratic Republic of Ethiopia, Central Statistical Agency, Agricultural sample survy report on livestock and livestock characterstics. II, 1-194.

CSA (Central Statistical Authority), 2013. Federal Democratic Republic of Ethiopia, Central Statistical Agency, Population projection of Ethiopia for all Regions at Wereda level from 2014 - 2017. Addis Ababa.

CSA (Central Statistical Authority), 2007. Federal Democratic Republic of Ethiopia, Central Statistical Agency, Population and housing census of Ethiopia: Administrative report By Central Statistical Authority.

Dagnachew, S., 2004. Epidemiology of bovine trypanosomosis in the Abbay basin areas of Northwest Ethiopia. MVSc thesis, Faculty of Veterinary Medicine, Addis Ababa University, Debre Zeit, Ethiopia.

Dagnachew, S., Tsegaye, B., Awukew, A., Tilahun, M., Ashenafi, H., Rowan, T., Abebe, G., Barry, D.J., Terefe, G., Goddeeris, B.M., 2017. Prevalence of bovine trypanosomosis and assessment of trypanocidal drug resistance in tsetse infested and nontsetse infested areas of Northwest Ethiopia. Parasite Epidemiol. Control., 2(2), $40-49$.

Delespaux, V., Geysen, D., Van den Bossche, P. and Geerts, S., 2008. Molecular tools for the rapid detection of drug resistance in animal trypanosomes. Trends in Parasitol., 24(5), 236-242.

Denu, T.A., Yilkal, A., and Tolossa, Y.H., 2012. Bovine trypanosomosis in three districts of Southwest Oromia, Ethiopia. Ethiop. Vet. J., 16(1), 23-39.

FEWSNET (Famine Early Warning Systems Network Informing Climate Change Adaptation Series), 2012. A Climate trend analysis of Ethiopia.

Giordani, F., Morrison, L.J., Rowan, T.G., De Koning, H.P., Barrett, M.P., 2016. The animal trypanosomiases and their chemotherapy: a review. Parasitology. 143(14), 1862-1889.

Hadush, B., Afera, B., Aregawi., Awol, N., Mulu, A., and Woldu, K., 2014. Preliminary study on mechanically transmitted bovine trypanosomosis and management 
of trypanocidal drugs in selected peasant associations of Tigray. Acta Parasitol. Globalis. 6(1), 36-41

IAEA (International Atomic Energy Agency), 1996. Government of Federal Democratic Republic of Ethiopia. Draft projects document integrating the Sterile Insect Technique to eradicate tsetse from the Southern Rift Valley of Ethiopia

Mekonnen, G., Mohammed, E.F., Kidane, W., Nesibu, A., Id, H.B., Yohannes, H., Reet, N. Van, Bu, P., 2018. Isometamidium chloride and homidium chloride fail to cure mice infected with Ethiopian Trypanosoma evansi type A and B. Plos Neglected Tropical Disease., 12(9), 1-12.

Moti, Y., Fikru, R., Van Den Abbeele, J., Büscher, P., Van den Bossche, P., Duchateau, L., Delespaux, V., 2012. Ghibe river basin in Ethiopia: present situation of trypanocidal drug resistance in Trypanosoma congolense using tests in mice and PCR-RFLP. Vet. Parasitol., 189(2), 197-203.

Mulugeta, W., Wilkes, J., Mulatu, W., Majiwa, P.A.O., Masake, R.,Peregrine, A.S. 1997. Long-term occurrence of Trypanosoma congolense resistant to diminazene, isometamidium and homidium in cattle at Ghibe, Ethiopia. Acta Trop., 64(3), 205-217.

Ngare, P.M.. and Mwendia, C.M.T., 2000. Tsetse and trypanosomosis: An epidemiological survey in Osupuko and Mara division of Narok district. In: Proceedings, 25th International Scientific Council for Trypanosomosis Research and Control (ISCTRC), September 27, 2000, Mombassa, Kenya.

NMSA (National Meteorological Services Agency), 2005. National meteorological services agency agrometeorological bulletin: seasonal agro meteorological bulletin.

Seyoum, Z., Terefe, G., Ashenafi, H., 2013. Farmers' perception of impacts of bovine trypanosomosis and tsetse fly in selected districts in Baro-Akobo and Gojeb river basins, Southwestern Ethiopia. BMC Vet Res., 9, 214 (2013).

Shiferaw, S., Muktar, Y., Belina, D., 2015. A review on trypanocidal drug resistance in Ethiopia. J. Parasitol. Vector Biol., 7(4), 58-66.

SOFED (South Omo Zone Finance and Economic Development), 2012. South Omo Zone Finance and Economic Development report (2004).

SOZLFD (South Omo Zone Livestock and Fishery Department), 2018. South Omo zone livestock and fishery department, zonal livestock survey data.

Taherdoost, H., 2017. Determining sample size; How to calculate survey sample size. Inter. J. Economics Management Systems. 2, 237-239

Tekle, T., Terefe, G., Cherenet, T., Ashenafi, H., Akoda, K.G., Abbeele, J., Van Den, Gari, G., 2018. Aberrant use and poor quality of trypanocides : a risk for drug resistance in south western Ethiopia. BMC Vet. Res., 14(4), 1-8. 
Tewelde, N., Abebe, G., Eisler, M., McDermott, J., Greiner, M., Afework, Y., Kyule, M., Münstermann, S., Zessin, K.-H., Clausen, P.H. 2004. Application of field methods to assess isometamidium resistance of trypanosomes in cattle in western Ethiopia. Acta Trop., 90(2), 163-170.

Tsegaye, B., 2014. In vivo drug sensitivity tests of Trypanosoma vivax isolates from selected tsetse infested and tsetse free areas of North West, Ethiopia. MVSc thesis. Addis Ababa University, College of Veterinary Medicne and Agriculture, Bishoftu, Ethiopia.

Van den Bossche, P., Doran, M. and Connor, R.J., 2000. An analysis of trypanocidal drug use in the Eastern Province of Zambia. Acta Trop., 75(2), 247-258.

W/yohannes, D., Kebede, E., and Abebe, G., 2010. Study on the assessment of drug resistance on Trypanosoma vivax in Tselemti woreda, Tigray, Ethiopia. Ethiop. Vet. J., 14(1), 15-30. 